\title{
Reġeneração aberrante do nervo oculomotor secundária a aneurisma intracraniano: relato de caso
}

\author{
Aberrant regeneration of the oculomotor nerve followed by intracranial \\ aneurysm: case report
}

Renato Wendell Ferreira Damasceno ${ }^{1}$ Maria Alice Rodrigues Corrêa ${ }^{2}$

\begin{tabular}{|l|}
\hline RESUMO \\
\hline Relatar um caso de regeneração aberrante secundária à paralisia aguda do \\
nervo oculomotor causada por aneurisma intracraniano. Paciente atendida \\
em fevereiro de 2006 queixando-se de dor de cabeça acompanhada de visão \\
dupla e queda da pálpebra no olho direito. Na avaliação da motilidade \\
ocular extrínseca, verificou-se incapacidade da adução, da supradução e \\
da infradução associada à blefaroptose no olho direito. Com relação à \\
motilidade intrínseca, midríase paralítica no olho direito. Formulou-se \\
diagnóstico de paralisia aguda de nervo oculomotor no olho direito e \\
solicitou-se avaliação neurológica. No Departamento de Neurocirurgia, \\
após ser diagnosticada presença de aneurisma de artéria comunicante \\
posterior, a paciente foi submetida a tratamento cirúrgico. Em dezembro de \\
2006, observou-se melhora relativa da adução, mantendo a incapacidade \\
da supradução e da infradução com blefaroptose melhorada à adução do \\
olho direito. Com relação à motilidade intrínseca, miose no olho afetado. \\
O diagnóstico de regeneração aberrante do nervo oculomotor pós-para- \\
lisia aguda foi formulado baseando-se na anamnese e nos exames oftalmo- \\
lógicos seqüenciais.
\end{tabular}

Descritores: Nervo oculomotor; Regeneração nervosa; Aneurisma intracraniano; Blefaroptose; Exotropia; Humanos; Feminino; Meia-idade; Relatos de casos [Tipo de publicação]

\section{INTRODUÇÃOO}

O nervo oculomotor ou III nervo craniano (NC III) constitui uma das mais complexas vias eferentes do sistema visual ${ }^{(1)}$. É responsável pela inervação dos músculos extra-oculares: reto superior, reto medial, reto inferior, oblíquo inferior e levantador da pálpebra superior ${ }^{(1-2)}$. Sabe-se, também, que possui fibras eferentes parassimpáticas responsáveis pela inervação dos músculos ciliar e esfíncter da pupila ${ }^{(1-2)}$. É descrito pela literatura que o nervo oculomotor origina-se de um complexo nuclear situado no mesencéfalo próximo ao colículo superior, ventralmente ao aqueduto de Sylvius ${ }^{(3-4)}$. Observa-se que o III nervo craniano, ao emergir da fossa interpeduncular, atravessa o espaço subaracnóideo, passando entre as artérias cerebelar superior e cerebral posterior. Trafega em paralelo com a borda do tentório e lateralmente à artéria comunicante posterior ${ }^{(4-7)}$. Perfura a aracnóide, localizando-se entre a borda livre e a borda aderente da tenda do cerebelo ${ }^{(4-7)}$. Posteriormente, perfura a lâmina interna da dura-máter, seguindo para frente junto à parede lateral do seio cavernoso e à artéria carótida interna ${ }^{(4-7)}$. Próximo à órbita, divide-se em ramo superior e ramo inferior, que passam pela fissura orbital superior, dentro do anel tendíneo comum ${ }^{(1,4-7)}$. 
É relatado que devido ao longo trajeto intracraniano e a sua íntima relação com estruturas vasculares, o nervo oculomotor é susceptível à lesão tanto por ressecção quanto por compressão, destacando: aneurisma de artéria comunicante posterior, hematomas subdural ou extradural e fístula carótido-cavernosa ${ }^{(2)}$. Além disso, é citada a vasculopatia isquêmica por diabetes mellitus ${ }^{(2-3)}$. Também, é descrita a paralisia do NC III após tromboflebite do seio cavernoso ${ }^{(8)}$.

A regeneração aberrante ou anômala do nervo oculomotor caracteriza-se por miose, elevação da pálpebra superior à adução ou à infradução ${ }^{(3)}$ e limitação do olhar vertical devido a uma reorganização axonal anormal ${ }^{(2)}$. Quando ocorrida após uma paralisia aguda, é chamada regeneração aberrante secundária ${ }^{(4-9)}$. Raramente, pode acontecer sem um antecedente de paralisia aguda, sendo denominada regeneração aberrante primária $^{(4)}$.

Para que haja uma regeneração anômala, é necessária lesão do endoneuro, o que ocorre nas compressões do nervo oculomotor $^{(2-3)}$; já nas lesões isquêmicas, este fato não é verificado, justificando a ausência regeneração aberrante após paralisia isquêmica ${ }^{(2-3)}$.

No presente relato, é observado um caso de regeneração aberrante secundária à paralisia aguda do nervo oculomotor causada por aneurisma de artéria comunicante posterior.

\section{RELATO DE CASO}

Paciente 59 anos de idade, negra, sexo feminino, aposentada, fluminense e procedente do Rio de Janeiro atendida no Serviço de Oftalmologia do Hospital Geral de Bonsucesso em fevereiro de 2006 queixando-se de dor de cabeça holocraniana, de forte intensidade, iniciada subitamente e acompanhada de visão dupla e queda da pálpebra do olho direito (OD). Com relação aos antecedentes, foi relatada hipertensão arterial sistêmica há 12 anos.

À ectoscopia, foram observadas exotropia e ptose palpebral no OD. Ao exame oftalmológico, acuidade visual de 20/30 no OD e 20/25 no olho esquerdo (OE) com correção óptica. Na avaliação da motilidade ocular extrínseca, verificou-se incapacidade da adução, da supradução e da infradução associada à ptose palpebral no OD e normalidade no OE. Na aferição do ângulo do desvio ocular, constatou-se 45 dioptrias prismáticas de base nasal. Na semiologia palpebral, função do músculo elevador da pálpebra superior de $4 \mathrm{~mm}$. Com relação à motilidade intrínseca, midríase paralítica no OD. Tonometria de aplanação de 14/14 mmHg às 8 horas. Biomicroscopia de segmento anterior e segmento posterior sem alterações em ambos os olhos (AO). Neste momento, formulou-se diagnóstico sindrômico de paralisia aguda de nervo oculomotor no OD. Inicialmente, solicitou-se parecer do Departamento de Neurocirurgia e tomografia computadorizada de crânio, a qual não demonstrou qualquer alteração. No Departamento de Neurocirurgia, foi solicitada arteriografia digital, sendo observado aneurisma de artéria comunicante posterior. Em março de 2006, foi submetida ao tratamento cirúrgico do aneurisma de artéria comunicante posterior. Pós-operatório sem intercorrências.

Em dezembro de 2006, retornando ao Departamento de Oftalmologia, observou-se permanência da exotropia (Figura 1).

Ao exame oftalmológico, acuidade visual de 20/30 no OD e 20/25 no OE com correção óptica. Avaliando-se a motilidade extrínseca, verificou-se melhora da adução, incapacidade da supradução, incapacidade da infradução e ptose palpebral melhorada à adução no OD (Figura 2) e normalidade no OE. Na aferição do ângulo do desvio ocular, constatou-se 20 dioptrias prismáticas de base nasal. Com relação à motilidade intrínseca, constricção pupilar no OD. Tonometria de aplanação de 16/14 mmHg às 10 horas. Biomicroscopia de segmento anterior e segmento posterior sem alterações em AO.

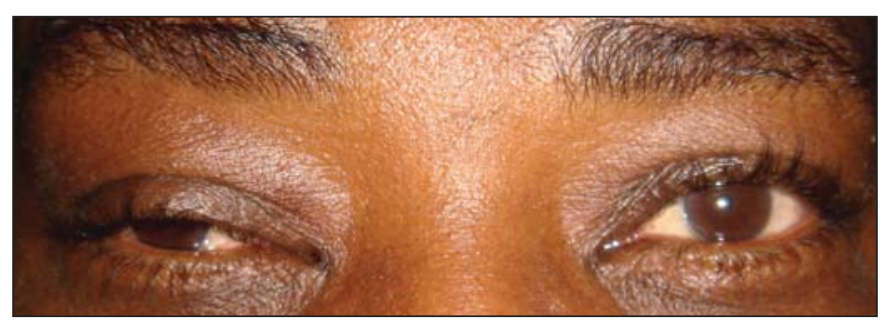

Figura 1 - Observar exotropia e blefaroptose no olho direito em posição primária

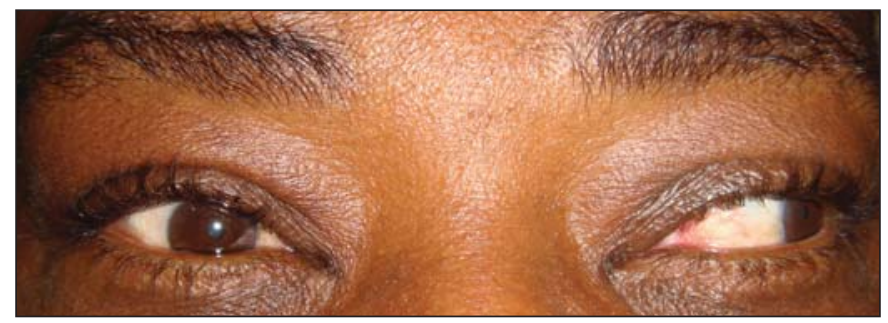

Figura 2 - Observar melhora da blefaroptose no olho direito durante levoversão

\section{DISCUSS ÃO}

A paralisia isolada do NC III é quase sempre originada no segmento basilar do nervo oculomotor (segmento entre o pedúnculo cerebral e o seio cavernoso) por uma lesão compressiva ${ }^{(2-3)}$. A identificação do aneurisma de artéria comunicante posterior foi realizada pela arteriografia digital, sendo o exame padrão-ouro $^{(3)}$.

Como afirmado anteriormente, para que ocorra uma regeneração anômala, é necessária lesão do endoneuro, o que pode ocorrer na síndrome compressiva do nervo oculomotor ${ }^{(2,4,6-7)}$.

No presente relato, observa-se um caso de regeneração aberrante secundária manifestado por constricção pupilar e elevação da pálpebra superior durante adução. Também, é verificada a permanência da incapacidade de supradução e infradução no olho acometido, ocorrendo apenas retorno parcial da capacidade de adução. 
O diagnóstico foi formulado baseando-se na anamnese e nos exames oftalmológicos seqüenciais, uma vez que houve história de paralisia aguda do III nervo craniano, evoluindo com exotropia e ptose palpebral ${ }^{(2-3,5-6)}$. Houve diminuição do ângulo da exotropia, permanecendo ptose palpebral melhorada à adução e limitação de supradução e infradução ${ }^{(3)}$.

\section{ABSTRACT}

To report a case of aberrant regeneration followed by acute palsy of the oculomotor nerve caused by intracranial aneurysm. A 59-year-old patient was attended in February 2006 complaining of headache with diplopia and blepharoptosis in the right eye. At the external ocular motility exam. Aduction, supraduction and infraduction defects with blepharoptosis in the right eye were observed. Regarding the internal ocular motility, mydriasis in the right eye. Acute palsy of the oculomotor nerve in the right eye was diagnosed and neurological examination was requested. At the Department of Neurosurgery, after having diagnosed aneurysm of the posterior communicating artery, the patient was submitted to an operation. In December 2006, it improvement of the aduction was observed, supraduction and infraduction defects remained and blepharoptosis improved during aduction of the right eye. In the internal ocular motility, miosis in the affected eye. The diagnosis of the aberrant regeneration of the oculomotor ner- ve after acute palsy was formulated based on anamnesis and ophthalmological follow-up tests.

Keywords: Oculomotor nerve; Nerve regeneration; Intracranial aneurysm; Blepharoptosis; Exotropia; Humans; Female; Middle aged; Case reports [Publication type]

\section{REFERÊNCIAS}

1. Dantas AM. Anatomia funcional do olho e seus anexos. Rio de Janeiro: Revinter; 2002.

2. Kanski JJ. Oftalmologia clínica: uma abordagem sistemática. São Paulo: Elsevier; 2003.

3. Winn HR, Youmans JR, editors. Youmans neurological surgery: introduction to neurological surgery and oncology. Philadelphia: Elsevier; 2004.

4. Dantas AM, Costa JG. Núcleo e subnúcleos de nervo oculomotor. Rev Bras Oftalmol. 1993;52(3):9-13.

5. Foung N, Wing L, Mendoza RM, Ramella MG. Regeneración aberrante del tercer nervio craneal: comunicación y análisis de uma serie de pacientes atendidos em um período de 17 años em la Unidad de Néuro-Oftalmología del Hospital Vargas de Caracas. Rev Oftalmol Venez. 1999;55(2):50-5.

6. Goonetilleke A, Yuill GM. Neurological picture. Aberrant regeneration of the third cranial nerve. J Neurol Neurosurg Psychiatry. 1996;60(3):281.

7. Pallini R, Fernandez E, Lauretti L, Draicchio F, Pettorossi VE, Gangitano C, et al. Experimental repair of the oculomotor nerve: the anatomical paradigms of functional regeneration. J Neurosurg. 1992;77(5):768-77.

8. Casella AM, Monteiro ML, Regensteiner DB, Caldeira JA. Regeneração aberrante do nervo oculomotor após tromboflebite do seio cavernoso. Arq Bras Oftalmol. 1988;51(3):135-7.

9. Watanabe A, Ishii R, Tanaka R. [Case of cerebral aneurysm producing the aberrant regeneration of the oculomotor nerve]. No To Shinkei. 1984;36(8): 743-7. Japanese. 